\title{
Muscle Activity Based on Real-time Visual Feedback Training Methods by Rehabilitative Ultrasound Image in Elderly and Relationship between Heckmatt Scale, Muscle Thickness and Tone : A Pilot Study
}

\author{
Janghoon Shin ${ }^{a}$, Wanhee Lee ${ }^{b}$ \\ aDepartment of Physical Therapy, Graduate School, Sahmyook University, Seoul, Republic of Korea \\ ${ }^{b}$ Department of Physical Therapy, Sahmyook University College of Health Science
}

Purpose: This study is to investigate the muscle activity based on real-time visual feedback training methods by rehabilitative ultrasound image in elderly and correlation between Heckmatt scale grade, muscle tone and thickness.

Design: Cross-sectional study: Pilot study

Methods: 6 elderly participated in the study with 2 conditions. Under the condition of rehabilitation ultrasound imaging equipment, all subjects performed voluntary maximal muscle contraction of the quadriceps 3 times using visual feedback based on Rehabilitative Ultrasound Imaging 1.0 (RUSI 1.0). Under the condition of only ultrasound images, all subjects performed voluntary maximal muscle contraction of the quadriceps 3 times using ultrasound image-based visual feedback. The muscle thickness and tone of the quadriceps were measured and the grades were classified by Heckmatt scale and all variables were comparative analyzed.

Results: Heckmatt scale grade showed a negative correlation with muscle thickness at relaxation $(\mathrm{p}<0.05)$, and a negative correlation with the difference value obtained by subtracting muscle thickness at relaxation from muscle thickness at contraction in ultrasound image condition $(\mathrm{p}<0.05)$. The muscle tone during relaxation showed a negative correlation with the muscle thickness during relaxation $(\mathrm{p}<0.05)$.

Conclusion: In the case of voluntary maximum muscle contraction of the quadriceps muscle in the elderly, it can be seen that the muscle thickness is getting larger when the RUSI 1.0-based visual feedback is provided than with only ultrasound image provided. And the lower Heckmatt scale grade is, the thicker the muscle is, and the lower the muscle tone is.

Key Words: Heckmatt scale, Quadriceps muscle, Ultrasonography, Visual feedback, Aged, Echogenicity

\section{서론}

세계보건기구(WHO)는 “2020-2030”년을 건강한 노화 의 10 년이라고 발표했으며[1], 고령화 사회에서는 얼마나 건강하게 노화가 되느냐가 관심거리가 되고 있다. 그러나 고령화 사회가 지속될수록 많은 질병과 질환에 노출되는 것이 현실이며 노화의 대표적 질환으로 근 감소증이 알려 져 있다[2]. 대부분의 노인들은 근 감소증 증상을 겪고 있 으며 근 감소증은 노인의 삶의 질을 떨어뜨린다[3, 4]. 이
러한 요인으로 인하여 재활관련 전문가들은 근 감소증을 예방하기 위한 다양한 연구들을 진행하고 있다 $[5,6]$.

많은 연구들 중 시각적 피드백을 이용한 재활 운동은 요 즘 대두되고 있는 관심분야이다. 근전도 장비, 초음파 영상 장비 등을 통하여 이러한 시각적 피드백을 재활이 필요한 대상자들에게 제공하고 있다 $[7,8]$. 특히 본 연구에서 다루 는 재활초음파영상장비는 시각적 피드백을 활용하는데 있 어서 다른 장비들에 비해 유용하게 쓰일 수 있다[9]. 재활 초음파영상장비는 다른 장비들과 다르게 근육의 형태학적

Received: Mar 9, 2021 Revised: Mar 15, 2021 Accepted: Mar 15, 2021

Corresponding author: Wanhee Lee (ORCID https://orcid.org/0000-0001-8030-4853)

Department of Physical Therapy, Sahmyook University College of Health Science

815, Hwarang-ro, Nowon-gu, Seoul, 01795 Republic of Korea

Tel: +82 233991633 Fax: +82 233991639 Email: whlee@syu.ac.kr

This is an Open-Access article distributed under the terms of the Creative Commons Attribution Non-Commercial License (http://creativecommons.org/licenses/ by-nc/4.0) which permits unrestricted non-commercial use, distribution, and reproduction in any medium, provided the original work is properly cited.

Copyright (C) 2021 Korean Academy of Physical Therapy Rehabilitation Science 
모습을 이미지상에 그대로 담아 내고 이를 실시간으로 화 면에 나타낸다. 환자들은 이러한 화면 상의 근육이 수축과 이완할 때의 모습을 실시간으로 확인하며 근 감소를 방지 하기 위해 재활 운동을 할 수 있다. 특히 복횡근과 같은 심 부근은 이러한 초음파 이미지 관찰을 통해 선택적 수축을 스스로 조절할 수 있다[7]. 또한, 재활초음파영상장비는 조 영제, 패드 등의 소모품이 불필요하여 경제적이고 시간과 장 소의 제약을 받지 않는 형태로 수시로 훈련에 이용할 수 있 어 환자에게도 치료의 효과성을 향상시킬 수 있다[10,11].

그러나 이와 같은 재활초음파영상장비의 장점에도 불 구하고, 초음파 이미지가 흑색과 백색으로만 표현되기 때 문에 비전문가에게 있어서는 이미지를 통한 해부학적 구 조를 감별하는 것이 어렵다는 단점이 있다[12]. 이는 시각 적 피드백 개념에 있어 다소 효과적이지 못할 수 있다는 점 으로 이어질 수 있다. 이러한 시각적 효과를 보완하고 극대 화하기 위해 재활초음파영상장비 VER 1.0이 이전 연구를 통해 개발되었고 그 효과성이 입증되었다[12]. RUSI 1.0 은 기존 초음파 이미지의 명암을 기반으로 한 실시간 근 두 께 변화율을 자동 추적하는 알고리즘을 도입하고 변화되 는 근 두께에 비례한 막대그래프 표출 기능이 있는 초음파 장비 연동 소프트웨어이다. 이전 연구에 따르면, 노인의 자 발적 최대 근 수축에 있어 RUSI 1.0 기반 시각적 피드백 근 수축 그룹이 구두 명령이나 단순 초음파 이미지만을 통 한 시각적 피드백 그룹보다 근 두께, 근 활성도에서 더 나 은 효과를 가져온다고 밝힌 바 있다[12]. 그러나 이전 연구 에서는 RUSI 1.0 을 이용한 훈련의 즉각적 효과만을 분석 한 연구적 한계가 있었다.

본 연구의 목적은 이러한 이전 연구의 한계를 보완하고 특히, 초음파 이미지만을 통한 시각적 피드백 효과와 RUSI 1.0 을 통한 시각적 피드백 효과 간의 차이를 집중적 으로 비교하여 알아보고자 하였다. 또한 초음파 이미지의 명암을 기반으로 한 Heckmatt Scale에 따른 근육 등급이 근 긴장도, 근 두께와는 어떠한 관계가 있는지도 추가적으 로 알아보고자 하였다. 본 연구의 가설은 다음과 같다. 1) RUSI 1.0 제공 시각적 피드백 훈련이 기존 초음파 이미지 만을 제공한 훈련보다 노인의 대퇴사두근 최대 수축 도중 평가한 근 두께가 더 커질 것이고, 2) Heckmatt 척도에 따 른 대퇴직근 등급은 근긴장도와 음의 상관관계를, 근 두께 와 양의 상관관계를 가질 것이다.

\section{연구 방법}

\section{연구 대상}

본 연구에서는 서울시에 거주하는 6 명의 노인(남성 3 명, 여성 3명)이 참가하였다. 선정 기준은 근골격계 질환이 없는 65 세 이상의 노인으로 연구자가 지시하는 내용을 이
해하고 따를 수 있는 인지능력이 있는 한국형 간이 정신검 사(mini mental state examination-Korean, MMSE-K)에 서 24점 이상인 자, 무릎의 정상 관절 가동 범위 내 가동이 가능한 자, 시각적 피드백을 볼 수 있는 시력과 구두 명령 을 따를 수 있는 청력을 가진 자로 하였다. 모든 대상자에 게는 코로나19 방역 대책을 준수하고 연구 목적과 연구의 필요한 정보에 대해 자세히 설명하고 연구 진행 도중 참가 를 원치 않을 경우 언제든지 연구에서 철회할 수 있음을 설 명한 후 연구 참여 동의서를 받았다. 본 연구는 삼육대학교 생명윤리위원회 승인을 받아 시행되었다.

\section{연구 설계}

본 연구의 설계는 파일럿 실험 연구로, 단면적-단일 집 단의 두 조건에 대한 실험연구이다.

\section{연구 절차}

본 연구는 단일 집단 두 조건에 대한 단면 연구 설계로 구성하였다. 6 명의 피험자는 모두 두 가지 다른 조건에 대 해 대퇴사두근 자발적 최대 근 수축을 3 회씩 1 회당 5 초간 시행하였다. 이 때, 재활초음파영상장비(PC-BMW)(MicrUs EXT-1H; TELEMED, Lithuania)를 통해 대퇴직근의 근 두께와 근 긴장도 측정장비(MyotonPro; Myoton AS, Estonia) 를 통해 근 긴장도를 측정하고 초음파 이미지를 저장하여 Heckmatt 척도에 따라 실험 후 대퇴직근의 등급을 육안으 로 초음파 이미지를 통해 분류하였다. 또한 1 회의 대퇴사 두근 이완시에도 동일하게 이와 같은 측정을 진행하였다. 두 조건은 조건 1) RUSI 1.0 기반 시각적 피드백을 제공하 여 대퇴사두근의 자발적 최대 근 수축 시행, 조건 2) 기존 초음파 이미지만을 이용하여 시각적 피드백을 제공하여 대퇴사두근의 자발적 최대 근 수축으로 나누어 시행하였 다. 모든 피험자는 단일 맹검법을 적용하였고 두 조건의 순 서는 무작위로 배정되었다. 실험 도중 근 피로가 유발되어 다음 회차의 실험에 영향을 끼치는 것을 방지하기 위해 각 회 사이에 20 초의 휴식을 취하게 하였고 두 조건 사이에는 먼저 시행한 조건에 대해 영향을 받지 않기 위해 5 분간의 충분한 휴식시간을 두었다.

모든 피험자는 무릎을 펴고 등을 기대 앉은 자세에서 측정을 진행하였다. 측정 변수별 측정 부위로는, 초음파 도 자는 슬개골 상단면으로부터 전상장골극 방향의 $60 \%$ 지 점에 두고 측정하였으며 근 긴장도 측정용 탐침은 초음파 도자 바로 아래 부분에서 측정하였다(Figure 1).

조건 1) RUSI 1.0을 활용한 시각적 피드백 제공 조건에 서는 피험자에게 모니터 상의 실시간 근 두께 변화에 비례 하여 색깔이 달라져 나타나는 막대 그래프를 직접 보면서 가능한 한 막대 그래프가 파란색에 가까워지게 근 수축을 하도록 설명하였다[12]. 모든 실험 참가자들에게 '모니터 상의 막대그래프가 파란색이 되도록 해당 근육에 힘을 주 


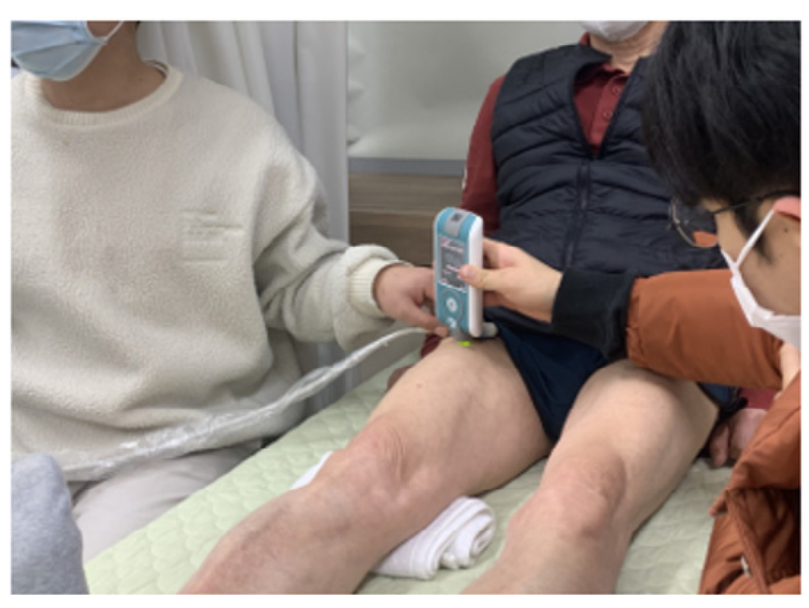

Figure 1. The location of quadriceps measurement
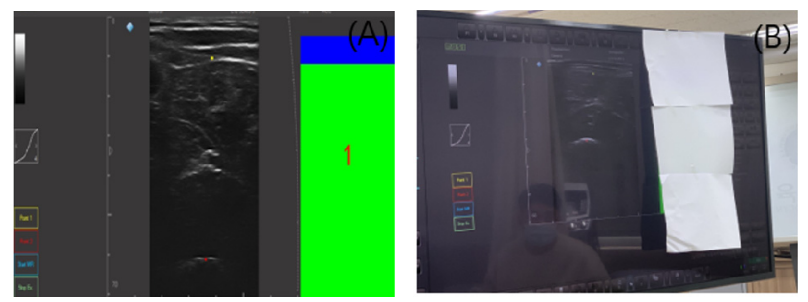

Figure 2. (A) Screen under condition using RUSI 1.0

(B) Screen under condition using only ultrasound image.

시고 5초간 유지하세요’라고 구두로 지시하였다.

조건 2) 기존 초음파 이미지를 활용한 시각적 피드백 제 공 조건에서는 피험자에게 모니터 상의 초음파 이미지에 서 근 수축 및 이완시 근육의 변화 양상에 대해 설명하고 이를 직접 보면서 수축시 근육이 가능한 한 늘어나도록 근 수축을 하게끔 설명하였다. 모든 연구대상자는 '모니터상 의 상대적으로 까맣게 보이는 근육이 최대한 늘어나도록 해당 근육에 힘을 주시고 5초간 유지하세요'라고 하였다 (Figure 2).

\section{측정 방법 및 도구}

\section{RUSI 1.0}

RUSI 1.0은 Personal Computer-Based Muscle Viewer (PC-BMW)와 연동하는 시각적 피드백 제공 소프트웨어 이다. 이 소프트웨어는 노인이 대퇴사두근의 등척성 수축 운동을 할 수 있도록 하는 도구로서, 초음파 이미지 데이터 사용을 기반으로 근 두께에 비례한 막대그래프를 생성하 는 것에 핵심이 있다. 이 소프트웨어의 활성화를 위하여 두 점이 위치하는데, 하나의 점은 대퇴직근 상부근막의 중앙 지점에 위치하고 다른 하나의 점은 대퇴골의 상단 경계에 위치한다. 두 점 모두 가장 고에코발생도 지점에 위치하고 따라서 근육이 수축할 시 두 점은 에코발생도를 기준으로
가장 고에코발생도 지점을 추적하게 된다. 두 점 사이의 수 직 거리는 근 두께를 의미하며 실시간으로 변하는 근 두께 에 비례하게 나타나는 막대 그래프를 생성한다. 막대 그래 프는 노인이 운동하는 도중 자발적 최대 근수축시 두께를 $100 \%$ 로 했을 때 실시간으로 변하는 근 두께의 비율에 따 라 4 가지 다른 색깔로 보여준다(>100\%: 파랑, 95\%-100\%: 초록, $88 \%-94 \%$ : 노랑, $<88 \%$ : 빨강). 화면에서 막대 그래 프가 파랑 혹은 초록색인 경우, 노인의 근수축을 유지하도 록 하기 위해 5 초의 타이머 기능이 활성화된다. 근수축 상 태를 평가하기 위해 측정 당일 가장 큰 근 두께 수치는 자 동으로 저장된다.

\section{자료 분석}

모든 조건에서 3회씩 측정된 대퇴사두근의 자발적 최 대 수축시 근 두께와 근 긴장도는 3 회의 평균값으로 산출 되었으며 5초간 수축이 유지되는 모든 회에서 중간 시점인 3 초때를 기준으로 순간 근 두께 및 근 긴장도를 측정하였 다. 근 두께는 RUSI 1.0 의 실시간으로 초음파 이미지상에 서 대퇴직근의 상부 근막과 넙다리벼의 상단 지점을 추적 하여 그 수직선상의 값을 계산해주는 자동 근 두께 측정 시 스템에 의해 산출하였고 각 피험자마다 순수한 수축시의 근 변화량을 확인하기 위해 수축시 근 두께에서 이완시 근 두께를 뺀 값의 평균으로 산출하였다. 근 긴장도는 MyotonPro 의 탐침이 근육을 눌렀을 때 반사되는 근육의 수동적 신장 에 대한 저항을 기반으로한 계산값을 반영하였다.

Heckmatt 척도에 따른 근육 등급은 재활영상 초음파 분야의 전문가와의 상의를 통해 Grade $1,2,3,4$ 중 하나로 채택하였다[13].

Heckmatt 척도는 수분함량이 많아 상대적으로 건강한 근 육일수록 근육 등급 중 가장 낮은 수치인 grade 1 에 가깝다.

각 피험자별 산출된 변수들을 정량적으로 파악하여 두 가지 다른 시각적 피드백 제공 조건별 변수들간의 관계에 대한 경향성을 확인하였다.

본 연구를 위한 자료처리 방법은 Windows용 SPSS ver 18.0(SPPS ver 18.0; SPSS Inc., USA) 통계 프로그램을 이용하였다. 각 집단의 평균과 표준편차는 기술분석으로 구하였고 각 측정 변인 간의 상관관계를 분석하기 위하여 Spearman correlation coefficient를 사용하였다. 연구 대 상자 6명에서 초음파 이미지 피드백군과 RUSI 1.0 피드백 군의 조건간 변수별 차이를 알아보기 위해 Wilcoxon signed rank test를 사용하였다. 모든 자료의 통계학적 유 의수준은 $\mathrm{p}<0.05$ 로 설정하였다. 


\section{연구 결과}

\section{연구참여자의 일반적 특성}

연구 대상자는 총 6 명으로(남자 3 , 여자 3) 평균 나이는 74.83(5.71)세, 평균 신장은 $158.75(8.41) \mathrm{cm}$, 평균 몸무 게는 56.63(12.58) $\mathrm{kg}$ 이고, 평균 $\mathrm{BMI}$ 는 22.17(3.39) $\mathrm{kg} /$ $\mathrm{m}^{2}$ 이였다(Table 1).

연구참여자의 근 긴장도, 근 두께 및 Heckmatt 척도 등급 측정 결과

\section{근 긴장도}

대퇴사두근의 자발적 최대 근수축시 피험자 6명의 평균 근 긴장도는 RUSI 1.0 기반 시각적 피드백 제공 조건에서 $15.48(2.03) \mathrm{Hz}$ 였고 초음파 이미지만을 통한 시각적 피드 백 제공 조건에서는 $15.20(1.91) \mathrm{Hz}$ 였다. 대퇴사두근 이완 시의 근 긴장도의 평균은 $12.38(1.23) \mathrm{Hz}$ 였다.

\section{근 두께}

대퇴사두근의 자발적 최대 근수축시 피험자 6명의 수축

Table 1. General Charateristics of Participants $\quad(n=6)$

\begin{tabular}{ll}
\hline Charateristics & Value \\
\hline Sex (female/male) & $3 / 3$ \\
Age (year) & $74.83(5.71)$ \\
Height $(\mathrm{cm})$ & $158.75(8.41)$ \\
Weight $(\mathrm{kg})$ & $56.63(12.58)$ \\
Body mass index $\left(\mathrm{kg} / \mathrm{m}^{2}\right)$ & $22.17(3.39)$ \\
\hline
\end{tabular}

Values are presented as number or mean (SD).
시 두께에서 이완시 근 두께를 뺀 차이값의 평균은 RUSI 1.0 기반 시각적 피드백 제공 조건에서 $18.09(6.35) \mathrm{mm}$ 였 고 초음파 이미지만을 통한 시각적 피드백 제공 조건에서 는 16.49(6.43) mm였다. 대퇴사두근 이완시의 근 두께의 평균은 19.61(2.41) $\mathrm{mm}$ 였다.

\section{Heckmatt scale}

대퇴사두근 중 대퇴직근의 Heckmatt 척도 등급은 6명 중 2 등급이 4 명, 3 등급이 2 명이었다. 6 명의 평균 등급은 2.33(0.52)등급이었다(Table 2).

\section{측정 변수간의 상관관계}

Heckmatt 척도와 근 긴장도, 근 두께 사이의 상관관계 는 Heckmatt 척도 등급과 초음파 이미지만을 제공하여 근 수축 두께에서 근 이완 시 두께를 뺀 차이값 사이에서 통계 적으로 높은 음의 상관관계가 있었고 $(\mathrm{p}<0.05) \mathrm{Heckmatt}$ 척도 등급과 이완시 근 두께에서는 높은 음의 상관관계가 있었다 $(\mathrm{p}<0.05)$. 이완시 근 긴장도와 이완시 근 두께 사이 에서 통계적으로 높은 음의 상관관계가 있었다 $(\mathrm{p}<0.05)$. 또한 RUSI 1.0 제공하여 근 수축 시의 근 긴장도와 초음파 이미지만을 제공하여 근 수축 시의 근 긴장도 사이에서 높 은 양의 상관관계가 있었다 $(\mathrm{p}<0.05)$. 다른 변수간의 상관 관계에 대해서는 통계적으로 유의하지는 않았고 경향성이 있는 것으로 확인되었다(Table 3).

\section{두 조건 사이의 근 두께, 근 긴장도 비교}

근 수축시 두께에서 근 이완시 두께를 뺀 차이값은 RUSI 1.0 시각적 피드백 조건과 초음파 이미지 시각적 피드백 조건 간에 통계학적인 차이가 근 두께 변화량은 유의하였고 $(\mathrm{p}<0.05)$ 근 긴장도 변화량은 유의하지 않았다(Table 4).

Table 2. Outcomes of Muscle tone, Muscle Thickness and Heckmatt Scale Grade

$(\mathrm{n}=6)$

\begin{tabular}{llllllll}
\hline Participants & Variables & & & & & & \\
\hline & HG & $\begin{array}{l}\text { MSWR } \\
(\mathbf{H z})\end{array}$ & $\begin{array}{l}\text { MSWU } \\
\mathbf{( H z )}\end{array}$ & $\begin{array}{l}\text { MSR } \\
\mathbf{( H z )}\end{array}$ & $\begin{array}{l}\text { DTWR } \\
(\mathbf{m m})\end{array}$ & $\begin{array}{l}\text { DTWU } \\
(\mathbf{m m})\end{array}$ & $\begin{array}{l}\text { TR } \\
(\mathbf{m m})\end{array}$ \\
$\mathrm{A}$ & & 15.47 & 15.47 & 13.20 & 16.01 & 13.69 & 16.48 \\
$\mathrm{~B}$ & 3 & 15.03 & 13.97 & 10.00 & 14.23 & 14.09 & 23.74 \\
C & 2 & 12.33 & 12.67 & 12.50 & 15.61 & 14.68 & 19.50 \\
D & 2 & 18.7 & 18.33 & 13.00 & 10.89 & 8.09 & 18.61 \\
E & 3 & 15.7 & 14.97 & 13.30 & 26.96 & 23.44 & 18.90 \\
F & 2 & 15.67 & 15.8 & 12.30 & 24.84 & 24.93 & 20.40 \\
Mean (SD) & $2.33(0.52)$ & $15.48(2.03)$ & $15.20(1.91)$ & $12.38(1.23)$ & $18.09(6.35)$ & $16.49(6.43)$ & $19.61(2.41)$ \\
\hline
\end{tabular}

HG: heckmatt scale grade, MSWR: muscle tone with RUSI 1.0, MSWU: muscle tone with ultrasound image, MSR: muscle tone at rest, DTWR: difference muscle thickness between with RUSI 1.0 and at rest, DTWU: difference muscle thickness between with ultrasound image and at rest. TR: muscle thickness at rest Values are presented as number or mean (SD). 
Table 3. Correlation between measurements

$(\mathrm{n}=6)$

\begin{tabular}{|c|c|c|c|c|c|c|c|c|}
\hline Variables & & HG & MSWR & MSWU & MSR & DTWR & DTWU & TR \\
\hline \multirow[t]{2}{*}{$\mathrm{HG}$} & $\mathrm{r}$ & 1 & 0.414 & 0.621 & 0.414 & -0.414 & $-0.828 *$ & $-0.828 *$ \\
\hline & $\mathrm{p}$ & & 0.414 & 0.188 & 0.414 & 0.414 & 0.042 & 0.042 \\
\hline \multirow[t]{2}{*}{ MSWR } & $\mathrm{r}$ & & 1 & $0.829^{*}$ & 0.486 & 0.086 & -0.143 & -0.429 \\
\hline & $\mathrm{p}$ & & & 0.042 & 0.329 & 0.872 & 0.787 & 0.397 \\
\hline \multirow[t]{2}{*}{ MSWU } & $\mathrm{r}$ & & & 1 & 0.200 & -0.086 & -0.257 & -0.429 \\
\hline & $\mathrm{p}$ & & & & 0.704 & 0.872 & 0.623 & 0.397 \\
\hline \multirow[t]{2}{*}{ MSR } & $\mathrm{r}$ & & & & 1 & 0.429 & -0.143 & $-0.829^{*}$ \\
\hline & $\mathrm{p}$ & & & & & 0.397 & 0.787 & 0.042 \\
\hline \multirow[t]{2}{*}{ DTWR } & $\mathrm{r}$ & & & & & 1 & 0.771 & -0.029 \\
\hline & $\mathrm{p}$ & & & & & & 0.072 & 0.957 \\
\hline \multirow[t]{2}{*}{ DTWU } & $\mathrm{r}$ & & & & & & 1 & 0.543 \\
\hline & $\mathrm{p}$ & & & & & & & 0.266 \\
\hline \multirow[t]{2}{*}{ TR } & $\mathrm{r}$ & & & & & & & 1 \\
\hline & $\mathrm{p}$ & & & & & & & \\
\hline
\end{tabular}

HG: heckmatt scale grade, MSWR: muscle tone with RUSI 1.0, MSWU: muscle tone with ultrasound image, MSR: muscle tone at rest, DTWR: difference muscle thickness between with RUSI 1.0 and at rest, DTWU: difference muscle thickness between with ultrasound image and at rest. TR: muscle thickness at rest $* \mathrm{p}<0.05$.

Table 4. Comparison of outcomes between two conditions

$(\mathrm{n}=6)$

\begin{tabular}{lll}
\hline & DT & DS \\
\hline $\mathrm{Z}$ & $-1.992^{*}$ & -1.214 \\
$\mathrm{p}$ & 0.046 & 0.225 \\
\hline
\end{tabular}

DT: difference muscle thickness between contraction and rest, DS: difference muscle tone between contraction and rest ${ }^{*} \mathrm{p}<0.05$.

\section{고찰}

고령층 노인의 대퇴사두근 근력은 걷거나 앉은 자세에 서 일어서기 등 기능적 활동을 수행할 때 매우 중요한 요소 이다[14]. 또한 대퇴사두근의 근력의 약화는 일상생활을 못하게 되어 의료기관 등에 수용될 수 있는 요인으로 제기 되는 등 노인 건강에 미치는 가치는 매우 높다고 할 수 있 다. 따라서 노인의 대퇴사두근을 강화하기 위해 여러 방법 들이 제시되고 있는데, 최근에는 인체의 다양한 생체 신호 를 인지하여 이를 디지털화시킴으로서 시각적 피드백을 이용한 융복합 장비들이 개발되고 임상적으로 다양한 대 상자들에게 재활훈련을 시키는 방법들의 연구들과 그에 따른 효과를 구명하는 연구가 많이 진행되고 있다[15]. 운 동 선수에게 매 훈련 직후 마다 시각적 피드백을 줌으로써
점프, 스쿼트 훈련을 했을 때의 효과나[16] 만성기 뇌졸중 환자를 대상으로 재활에 중요한 앉은 자세 균형을 잡아주 기 위해 앉은 자세에서의 무게 중심을 센서가 인지하고 실 시간으로 무게 중심의 이동을 모니터에 표시하여 재활 훈 련을 했을 때의 효과[17], 양측성 뇌성마비 아이들을 대상 으로 족부의 가벼운 압력을 인지하고 시각적으로 표시해 주는 장비를 사용하여 보행 훈련을 하였을 때의 효과[18] 등 다양하다.

그러나 시각적 피드백을 위한 시스템으로 압력 센서를 이용한 무게 중심의 이동을 실시간으로 인지 및 모니터에 표출하는 장비들이 대상자의 균형 훈련에 끼치는 영향에 대한 연구들[17-20]은 다양하나 근육 두께의 실질적 두께 의 변화량을 기반으로 한 연구는 미비하다. 근육 두께는 근 육의 힘에 비례한 관계를 가지고 있고[21] 고령화 시대에 맞물려 노인의 근쇠약증에 따른 이러한 근 두께의 감소를 방지해야 삶의 질을 향상시킬 수 있다 $[3,4]$. 본 연구는 평 균나이 74.83세의 건강 노인 6명을 대상으로 실험한 것으 로, 실제로 근 감소증이 주로 발생하기 시작하는 나이에 해 당하는 노인을 대상으로 하여 본 연구를 통해 근 감소증을 예방하고자 하는 최종 목적에 적합한 대상자들로 연구를 진행하였다[22]. 기존 방식이었던 초음파 이미지만을 통하 여 시각적 피드백을 제공한 조건에서 무릎을 펴고 앉은 자 세에서의 대퇴사두근 자발적 최대 근수축시 근 두께의 변 
화와 재활초음파 영상을 통한 시각적 피드백 효과를 극대 화하는 것을 목표로 하여 개발한 RUSI 1.0 시스템을 통한 시각적 피드백이 대퇴사두근 자발적 최대 근 수축시 근 두 께에 얼마나 효과적으로 차이가 있는지를 구명하고, 나아 가 Heckmatt 척도에 따른 등급과 근 긴장도, 근 두께 사이 에 어떠한 관계가 있는지를 알아보기 위하여 실시하였다.

이 연구에서 다루는 RUSI 1.0 시스템은 이러한 현대사 회의 증가하는 노인 대상 근육 중심 재활 훈련의 필요성에 있어서 재활영상초음파를 통해 근 두께의 실질적 변화를 실시간으로 감지하고 이를 시각적 효과의 극대화를 위한 막대 그래프로 구현한다는 점이 새롭고 기존의 다른 시각 적 피드백들과의 가장 큰 차이점이다.

Heckmatt 척도는 1982년 Heckmatt 등이 근육 에코발 생도를 기준으로 시각적 등급을 나눈 것이다[13]. 본 연구 에서는 Heckmatt 척도에 의한 노인의 대퇴직근 등급이 MyotonPro 측정에 의한 근 긴장도와 근 두께 사이에서 어 떠한 상관관계가 있는지를 알아보고자 하였다. 본 연구에 참여한 노인은 65 세 79세까지(평균나이 74.73세) 남녀 성비가 동일하였고 신경학적 손상 및 기타 질병에 의한 근 골격계의 이상이 없었고 Heckmatt 척도 기준 등급이 뼈와 의 구별 정도가 줄어들고 조직의 에코발생도가 $50 \sim 90 \%$ 증가된 수준인 3 등급에 해당하는 피험자는 여자 2명, 남자 0 명이었고 근 조직의 $10 \sim 50 \%$ 의 에코발생도가 증가했으 나 뼈의 에코발생도와는 구분이 되는 수준인 2 등급에 해당 하는 피험자는 여자 1 명, 남자 3 명이었다. 이는 노인 남자 의 근육 상태가 노인 여자의 근육보다 수분함량이 상대적 으로 높기 때문인 것으로 보여진다[23].

Heckmatt 척도 기준 등급이 낮은 피험자일수록 상대 적으로 근 긴장도는 근 수축시와 이완시에서 모두 낮게 측 정되었다. 이는 Heckmatt 척도 기준 등급상 상대적으로 높 은 근육이 근 조직내에 섬유화가 노화에 의해 많이 진행되 었기 때문인 것으로 보여진다[24]. 섬유화가 많이 진행될 수록 초음파 이미지상에서는 고 에코로 나타나고 이는 근 육 고유의 탄력이 줄어들고 다소 경직된 상태로 특징되어 지기 때문이다[25].

본 연구에서 설계한 두 가지 다른 시각적 피드백 조건 (RUSI 1.0 기반과 초음파 이미지 기반에서의 시각적 피드 백 제공)에 따라서는 근 긴장도가 크게 달라지지 않는 것으 로 나타났다. 따라서 시각적 피드백의 방법을 달리하더라 도 피험자의 근 긴장도에는 즉각적인 차이가 나타나지 않 는다고 보여진다. 근 조직내의 섬유화가 이미 진행되었기 때문에 피험자의 활성화된 운동신경의 지배를 받는 근 섬 유다발의 수의적 수축만 일어나는 것은 그 수의적 수축 정 도의 차이가 해당 근육 전체 부분의 근 긴장도에 영향을 끼 치지는 않는 것이 원인으로 보여진다[26].

하지만 RUSI 1.0 을 통해 시각적 피드백을 제공한 조건
이 기존에 재활 운동에 사용하던 방식인 초음파 이미지만 을 통한 시각적 피드백을 제공한 조건에서보다 근 두께에 있어서는 차이가 있었다. 이는 초음파 이미지만을 통한 시 각적 피드백 제공 조건에서는 재활 운동 대상자가 이미지 상에서 근 수축이 실시간으로 얼마만큼 이루어지고 있는 지 정량적으로 확인하기 힘들지만 실시간 근두께 변화를 감지하고 변화량에 비례하게 색깔을 달리한 막대그래프를 표출하는 시스템인 RUSI 1.0 을 활용하면 대상자가 직접 실시간으로 자신의 근 재활 운동중인 근 두께가 실질적으 로 얼만큼 두꺼워지고 있는지를 그래프를 통해 확인할 수 있고 일정 수치 간격으로 그래프의 색깔도 변하기 때문에 운동에 대한 동기도 생길 수 있기 때문으로 보여진다[12]. 또한 기존의 초음파 이미지와는 다르게 RUSI 1.0 은 동시 적으로 근 두께의 변화를 그래프로 지연시간 없이 나타내 고 그래프에 대한 초기 적응 시간이 적기 때문에 초음파 이 미지만을 통한 피드백 조건에 비해 더 나은 결과가 나타난 것으로 보여진다[27, 28].

본 연구는 파일럿 시험으로 실험 대상자의 수가 적어 연 구의 결과를 통계학적으로 유의하는가에 대한 여부나 일 반화를 시키기에는 한계가 있어 그 경향성에 대한 파악에 목적과 의의를 두었다. 따라서 본 연구를 통해 도출된 경향 성을 바탕으로 대상자 수를 늘려 통계학적으로 유의한 결 과를 나타내는지 확인할 추후 연구가 필요하다.

\section{이익 충돌}

본 논문 출판에 있어 저자의 잠재적인 이익 충돌은 없음 을 밝힌다.

This work was supported by a National Research Foundation grant funded by the Korean government (no. NRF-2018R1D1A1B0704287013).

\section{참고 문헌}

1. Rudnicka E, Napierala P, Podfigurna A, Meczekalski B, Smolarczyk R, Grymowicz M. The World Health Organization (WHO) approach to healthy ageing. Maturitas. 2020;139:6-11.

2. Zampieri S, Mosole S, Lofler S, Fruhmann H, Burggraf S, Cvecka J, et al. Physical Exercise in Aging: Nine Weeks of Leg Press or Electrical Stimulation Training in 70 Years Old Sedentary Elderly People. Eur J Transl Myol. 2015;25:237-42.

3. Hairi NN, Cumming RG, Naganathan V, Handelsman DJ, Le Couteur DG, Creasey H, et al. Loss of muscle strength, mass (sarcopenia), and quality (specific force) 
and its relationship with functional limitation and physical disability: the Concord Health and Ageing in Men Project. J Am Geriatr Soc. 2010;58:2055-62.

4. Janssen I, Heymsfield SB, Ross R. Low relative skeletal muscle mass (sarcopenia) in older persons is associated with functional impairment and physical disability. J Am Geriatr Soc. 2002;50:889-96.

5. Sardeli AV, Komatsu TR, Mori MA, Gaspari AF, Chacon-Mikahil MPT. Resistance Training Prevents Muscle Loss Induced by Caloric Restriction in Obese Elderly Individuals: A Systematic Review and Meta-Analysis. Nutrients. 2018;10.

6. Landi F, Marzetti E, Martone AM, Bernabei R, Onder G. Exercise as a remedy for sarcopenia. Curr Opin Clin Nutr Metab Care. 2014;17:25-31.

7. Lee DH, Hong SK, Lee YS, Kim CH, Hwang JM, Lee $\mathrm{Z}$, et al. Is abdominal hollowing exercise using real-time ultrasound imaging feedback helpful for selective strengthening of the transversus abdominis muscle?: A prospective, randomized, parallel-group, comparative study. Medicine (Baltimore). 2018;97: e11369.

8. Arvanitidis M, Falla D, Martinez-Valdes E. Can visual feedback on upper trapezius high-density surface electromyography increase time to task failure of an endurance task? J Electromyogr Kinesiol. 2019;49: 102361.

9. McKiernan S, Chiarelli P, Warren-Forward H. A survey of diagnostic ultrasound within the physiotherapy profession for the design of future training tools. Radiography. 2011;17:121-5.

10. Choi MS, Shin JH, Park HK, Lee WH. Reliability and validity of rehabilitative ultrasound images obtained using a hands-free fixed probe in measuring the muscle structures of the tibialis anterior and the gastrocnemius. Phys Ther Rehabil Sci. 2019;8:194-201.

11. Cho JE, Cho KH, Yoo JS, Lee SJ, Lee WH. Reliability and validity of a dual-probe personal computer-based muscle viewer for measuring the pennation angle of the medial gastrocnemius muscle in patients who have had a stroke. Top Stroke Rehabil. 2018;25:6-12.

12. Shin JH, Lee WH. The effects of two different visual feedback exercise tools based on rehabilitative ultrasound imaging in the elderly. Phys Ther Rehabil Sci. 2020;9:287-94.

13. Moreta MC, Fleet A, Reebye R, McKernan G, Berger M, Farag J, et al. Reliability and Validity of the Modified Heckmatt Scale in Evaluating Muscle Changes With Ultrasound in Spasticity. Arch Rehabil Res Clin Transl. 2020;2:100071.

14. Do K, Yim J. Effects of Muscle Strengthening around the Hip on Pain, Physical Function, and Gait in Elderly Patients with Total Knee Arthroplasty: A Randomized Controlled Trial. Healthcare (Basel). $2020 ; 8$.

15. Zijlstra A, Mancini M, Chiari L, Zijlstra W. Biofeedback for training balance and mobility tasks in older populations: a systematic review. J Neuroeng Rehabil. 2010;7:58.

16. Vanderka M, Bezak A, Longova K, Krcmar M, Walker S. Use of Visual Feedback During Jump-Squat Training Aids Improvement in Sport-Specific Tests in Athletes. J Strength Cond Res. 2020;34:2250-7.

17. Pellegrino L, Giannoni P, Marinelli L, Casadio M. Effects of continuous visual feedback during sitting balance training in chronic stroke survivors. J Neuroeng Rehabil. 2017;14:107.

18. Hussein ZA, Salem IA, Ali MS. Effect of simultaneous proprioceptive-visual feedback on gait of children with spastic diplegic cerebral palsy. J Musculoskelet Neuronal Interact. 2019;19:500-6.

19. Zhao W, You H, Jiang S, Zhang H, Yang Y, Zhang M. Effect of Pro-kin visual feedback balance training system on gait stability in patients with cerebral small vessel disease. Medicine (Baltimore). 2019; 98:e14503.

20. Pignolo L, Basta G, Carozzo S, Bilotta M, Todaro MR, Serra S, et al. A body-weight-supported visual feedback system for gait recovering in stroke patients: A randomized controlled study. Gait Posture. 2020;82:287-93.

21. Lee HJ, Lee KW, Lee YW, Kim HJ. Correlation between Cycling Power and Muscle Thickness in Cyclists. Clin Anat. 2018;31:899-906.

22. Kwon HJ, Ha YC, Park HM. Prevalence of 
Sarcopenia in the Korean Woman Based on the Korean National Health and Nutritional Examination Surveys. J Bone Metab. 2016;23:23-6.

23. Serra-Prat M, Lorenzo I, Palomera E, Ramirez S, Yebenes JC. Total Body Water and Intracellular Water Relationships with Muscle Strength, Frailty and Functional Performance in an Elderly Population. J Nutr Health Aging. 2019;23:96-101.

24. Stokman M, Lilien M, Knoers N. Nephronophthisis. In: Adam MP, Ardinger HH, Pagon RA, Wallace SE, Bean LJH, Mirzaa G, et al., editors. GeneReviews((R)). Seattle (WA)1993.

25. Santos A, Lagares D. Matrix Stiffness: the Conductor of Organ Fibrosis. Curr Rheumatol Rep. 2018;20:2.

26. Nishimune H, Shigemoto K. Practical Anatomy of the Neuromuscular Junction in Health and Disease. Neurol Clin. 2018;36:231-40.

27. McKenna E, Bray LCJ, Zhou W, Joiner WM. The absence or temporal offset of visual feedback does not influence adaptation to novel movement dynamics. J Neurophysiol. 2017;118:2483-98.

28. Malone LA, Vasudevan EV, Bastian AJ. Motor adaptation training for faster relearning. J Neurosci. 2011;31:15136-43. 